\title{
Protocol
}

\section{Induction of Germline Apoptosis in Caenorhabditis elegans}

\author{
Benjamin Lant ${ }^{1}$ and W. Brent Derry ${ }^{2,3}$ \\ ${ }^{1}$ Developmental and Stem Cell Biology Program, The Hospital for Sick Children, Toronto, Ontario M5G 1L7, \\ Canada; ${ }^{2}$ Department of Molecular Genetics, University of Toronto, Toronto, Ontario M5S 1A1, Canada
}

RNA interference (RNAi) is an incredibly powerful tool for rapid and efficient knockdown of gene expression. This technology can be used to induce apoptosis in the germline of Caenorhabditis elegans. Genotoxic stressors such as ionizing radiation (IR), ultraviolet light, chemical mutagens (e.g., $N$-ethyl$\mathrm{N}$-nitrosourea [ENU]), and DNA cross-linking reagents can also be used to stimulate apoptosis. These approaches, described here, combined with the powers of in vivo imaging methods, should keep $C$. elegans apoptosis researchers busy for several years, sorting out how various signaling pathways influence life and death decisions in this organism.

\section{MATERIALS}

It is essential that you consult the appropriate Material Safety Data Sheets and your institution's Environmental Health and Safety Office for proper handling of equipment and hazardous material used in this protocol.

RECIPES: Please see the end of this protocol for recipes indicated by $<R>$. Additional recipes can be found online at http://cshprotocols.cshlp.org/site/recipes.

\section{Reagents}

Caenorhabditis elegans strain of interest (e.g., lin-35[n745], rrf-1[pk1417], or rrf-3[pk1426])

L1 larval stage worms are typically used for the RNAi procedure (see Step 5), whereas 44 worms are used for IR or ENU treatments (see Steps 6 and 8). The hypochlorite method is a standard technique that is used to synchronize worms to the $L 1$ larval stage, as well as to remove contamination. This procedure, along with many other basic worm handling techniques, can be found in Wormbook (Stiernagle).

ENU (Sigma-Aldrich N3385)

Freshly dilute the ENU stock solution to $5 \mathrm{~mm}$ in M9 buffer $<R>$ each time it is used.

HT115 bacteria (see Step 1)

Isopropylthio- $\beta$-galactoside (IPTG) $(0.1 \mathrm{~m})$

Luria Bertani $(\mathrm{LB})+$ amp and tet $<\mathrm{R}>$

Prepare both liquid medium and plates containing solid medium.

OP50 bacteria (optional; see Steps 6-9)

Plates containing solid nematode growth medium (NGM) $<\mathrm{R}>$

Plates containing solid RNAi medium $<\mathrm{R}>$

RNAi clones from the C. elegans RNAi feeding library (Source BioScience LifeSciences; see Discussion)

${ }^{3}$ Correspondence: brent.derry@sickkids.ca

(C) 2014 Cold Spring Harbor Laboratory Press

Cite this protocol as Cold Spring Harb Protoc; doi:10.1101/pdb.prot080192 
B. Lant and W.B. Derry

Bacterial RNAi lawns plated on NGM plates remain useful for experiments when stored at $4^{\circ} \mathrm{C}$ for $\sim 1$ mo. However, in our experience, some RNAi bacterial strains do not last this long when stored in the cold. If you plan to use a particular RNAi feeding strain repeatedly, we recommend preparing your own glycerol stock and storing it at $-80^{\circ} \mathrm{C}$ to avoid repeated access of the stock library.

Equipment

Gamma ( ${ }^{137} \mathrm{Cs}$ source), X, or UV irradiator

Imaging setup (see Protocol: Visualizing Apoptosis in Embryos and the Germline of Caenorhabditis elegans [Lant and Derry 2014])

For high-resolution imaging and quantification of apoptotic bodies, we recommend a compound microscope that is equipped with differential interference contrast (DIC) optics (63× oil immersion lens).

Incubators at $20^{\circ} \mathrm{C}$ and $37^{\circ} \mathrm{C}$

Microcentrifuge tubes $(0.5 \mathrm{~mL})$

Orbital shaker at $37^{\circ} \mathrm{C}$

P200 tips (sterile)

Tubes (15-mL conical)

\section{METHOD}

\section{Examining Apoptosis Using RNAi}

1. Select a targeted RNAi clone of interest from the C. elegans RNAi feeding library. Using a sterile P200 tip, streak from the glycerol stock onto a plate containing LB + amp and tet. Incubate the plates overnight at $37^{\circ} \mathrm{C}$.

Streaking the plate in a cross hatch pattern is optimal for creating single colonies.

A negative control consisting of an empty RNAi plasmid (or a gene with no strong RNAi phenotype) in the HT115 bacterial strain should be cultured concurrently.

2. On the next day, harvest individual colonies with a sterile P200 tip and transfer to 15-mL conical tubes containing $4 \mathrm{~mL}$ of liquid $\mathrm{LB}+\mathrm{amp}$ and tet. Grow overnight on an orbital shaker at $37^{\circ} \mathrm{C}$.

Liquid RNAi cultures can be stored at $4^{\circ} \mathrm{C}$ for up to $2 \mathrm{wk}$ for repeated use.

See Troubleshooting.

3. On the next day, add $20 \mu \mathrm{L}$ of $0.1 \mathrm{M}$ IPTG to each culture and incubate an additional $4 \mathrm{~h}$ on the shaker at $37^{\circ} \mathrm{C}$.

IPTG induces T7 RNA polymerase in the RNAi bacteria.

4. Spread $70 \mu \mathrm{L}$ of each bacterial culture on plates containing solid RNAi medium, and allow the bacteria to grow overnight at room temperature.

Ensure that lids are kept on the plates during the overnight growth period to prevent contamination. See Troubleshooting.

5. Add L1-stage worms to the bacterial lawn and allow them to grow until they are at the correct stage to observe apoptosis phenotypes (either young adult for germline apoptosis or after they have begun to lay eggs in the next generation for embryonic apoptosis). Proceed to Step 10.

Typically worms are placed onto RNAi-expressing bacterial lawns at the L1 stage, but if the targeted gene is essential, plating at the L3 or L4 stage may be necessary to observe a strong loss-of-function phenotype without affecting viability of the organism.

See Troubleshooting.

\section{Examining Apoptosis with Genotoxic Agents}

$I R$ is an efficient genotoxic stressor and causes no obvious morphological changes to somatic tissues. It activates the DNA damage response, thereby stimulating germline apoptosis. As an alternative, alkylating agents such as ENU can be used. 


\section{Inducing Apoptosis Using Irradiation}

6. One day before irradiation, pick 25 to 40 worms from a plate at the L4 stage. Place the worms on a new NGM plate (seeded with OP50 bacteria if using a mutant strain or the desired RNAi bacterial strain if assessing the apoptosis phenotype of a particular gene after knockdown). Allow the plate to incubate overnight at $20^{\circ} \mathrm{C}$.

See Troubleshooting.

7. On the next day, expose the worms (now at the young adult stage) to a dose of IR (0-120 Gy). Allow them to recover overnight, and proceed to Step 10.

If there is uncertainty as to what duration of radiation will be most effective to institute a quantifiable effect, the standard starting point should be $60 \mathrm{~Gy}$. If the strain is suspected to have apoptotic resistance, $120 \mathrm{~Gy}$ should be applied initially. The irradiated strain should be run alongside equally staged controls (N2) to compare the effects of the treatment.

\section{Inducing Apoptosis Using ENU}

8. Pipette $1 \mu \mathrm{L}$ of $5 \mathrm{~mm}$ ENU into the lid of a $0.5-\mathrm{mL}$ microcentrifuge tube anchored on the surface of a small, seeded NGM plate (i.e., in the bacteria). Add 20 worms at the L4 or young adult stage to the ENU solution and incubate in the dark for $4 \mathrm{~h}$ at $20^{\circ} \mathrm{C}$, with the plate inverted to prevent evaporation.

Because of the surface tension, using this small volume will prevent the dissolved ENU and worms from falling out of the lid when inverted. Just be careful not to bump the plate too hard when moving.

9. Following incubation, carefully pipette the worms onto a new NGM plate (seeded with OP50 bacteria or target RNAi) and allow them to recover from the ENU treatment. On the next day, proceed to Step 10.

\section{Analyzing Apoptosis}

10. Observe and quantify corpses using DIC microscopy with a $63 \times$ oil immersion lens.

Quantification of apoptosis and morphological analysis is described in Protocol: Visualizing Apoptosis in Embryos and the Germline of Caenorhabditis elegans (Lant and Derry 2014). It is imperative to perform at least three independent biological replicates when quantifying germline apoptosis, as this tissue shows more variability compared with developmentally programmed cell death in the invariant somatic lineages. For initial characterization of putative apoptosis-defective mutants, we recommend performing a time course analysis (e.g., 6-48 h post-IR) to define the kinetics of corpse formation.

Problem (Step 2): The bacterial streak is too thick to pick individual colonies.

Solution: This is the result of too many bacteria on the pipette tip or incubating for too long, causing colony overgrowth. Restreak from the stock and incubate for less time $(18 \mathrm{~h})$. Make sure the bacterial culture is not grown for longer than $24 \mathrm{~h}$.

Problem (Step 4): Contamination is present on the bacterial plates.

Solution: Make sure the plate lids are closed to prevent foreign particles from contaminating the bacterial plate. If the glycerol stock is contaminated, pick several individual colonies, verify the presence of the plasmid containing the desired RNAi clone by sequencing or restriction mapping, and grow a new liquid culture. It is also possible that the stock solutions used to prepare the plates or liquid RNAi cultures are contaminated. This can be tested by plating solutions on bacterial growth plates to see if contaminating bacteria grow after $24 \mathrm{~h}$ at $37^{\circ} \mathrm{C}$. Finally, the worms plated may contain contaminating bacteria. Some worm strains have a greater capacity for contamination (because of storage of bacteria in their gut), and as such the bleaching protocol (Stiernagle) can be modified by adding an extra two bleach wash steps followed by three sterile $\mathrm{H}_{2} \mathrm{O}$ washes. 
B. Lant and W.B. Derry

Problem (Step 5): RNAi does not provide the expected phenotype, if a phenotype is expected.

Solution: The particular RNAi may not have full penetrance and may require a second generation to show conserved effects. Alternatively, the single colony picked to produce the liquid culture may not have been effective; sometimes, the HT115 strain will mutate plasmids. Pick multiple colonies (making sure to stick to the "lines" of inoculation) and check individually isolated clones for the desired phenotype. However, it may be necessary to reclone the worm gene fragment into a fresh L4440 vector and retransform HT115 bacteria. This has worked well for the ced-9 RNAi bacteria strain, which we have observed to frequently become ineffective for gene knockdown by the feeding method.

Problem (Step 5): RNAi does not provide a strong phenotype.

Solution: As mentioned above, cultivating the worms on the target RNAi for a further generation may increase the consistency of any phenotypes seen. Alternatively, if the knockdown phenotype is not penetrant we recommend using strains carrying mutations in genes that cause hypersensitivity to RNAi, such as $r r f-3(p k 1426)$ or lin-35(n745) (Simmer et al. 2002; Lehner et al. 2006).

Problem (Step 5): RNAi is too toxic or causes morphological defects that make it difficult to observe apoptosis phenotypes.

Solution: Strains that are resistant to RNAi in the soma, such as the $r r f-1$ (pk1417) mutant (Sijen et al. 2001), can be used to selectively ablate genes in the germline. These strains should be used when ablation in the soma causes morphological defects that make assessment of the germline difficult. However, caution should be exercised when using $r r f-1$ alleles, as it has been recently reported that these mutants are not resistant to RNAi in all somatic tissues (Kumsta and Hansen 2012).

Problem (Step 6): The L4 stage has been missed, and there is an imperative to irradiate as soon as possible.

Solution: Worms can be irradiated on the same day, provided that they are distinctly at the young adult stage. Hence, the operator must be able to distinguish the stages of adulthood efficiently. Apoptotic nuclei in the germline are difficult to see as the worm ages because the intestine accumulates fat that can occlude the bends of the gonad arms, where apoptosis is detectable.

RNAi is not always $100 \%$ efficacious, as it causes a reduction in gene function that can be variable in penetrance-compared to the complete loss of function in null mutants or consistent reduction in function of hypomorphic alleles. The main advantages of using RNAi are the incredible ease and speed with which the function of a particular gene can be ascertained. The results from RNAi gene ablation, while not always as penetrant and consistent as those obtained using mutant strains, can be used to systematically screen multiple gene targets concurrently and rapidly. But care must be taken in both culturing RNAi clones and assessing phenotypes. We recommend confirming the identity of RNAi clones by sequencing or restriction mapping and using mutant strains to confirm RNAi phenotypes and epistatic interactions with other genes. Observing a phenotype by RNAi may not be effective or reproducible in the first generation, depending on the nature of the gene or the RNAi clone. This will require troubleshooting, either of the developmental stage when the worms are placed on the RNAi feeding strains or of the number of generations on RNAi necessary to obtain a penetrant phenotype.

The Source BioScience LifeSciences RNAi feeding library provides an extensive array of RNAi clones stored as frozen glycerol stocks in a 384-well plate format. This library represents over $86 \%$ of the predicted genes in the C. elegans genome, including almost all known apoptosis genes. For control experiments, RNAi ablation of core apoptosis pathway genes (Fig. 1) can be used to ensure that assays 

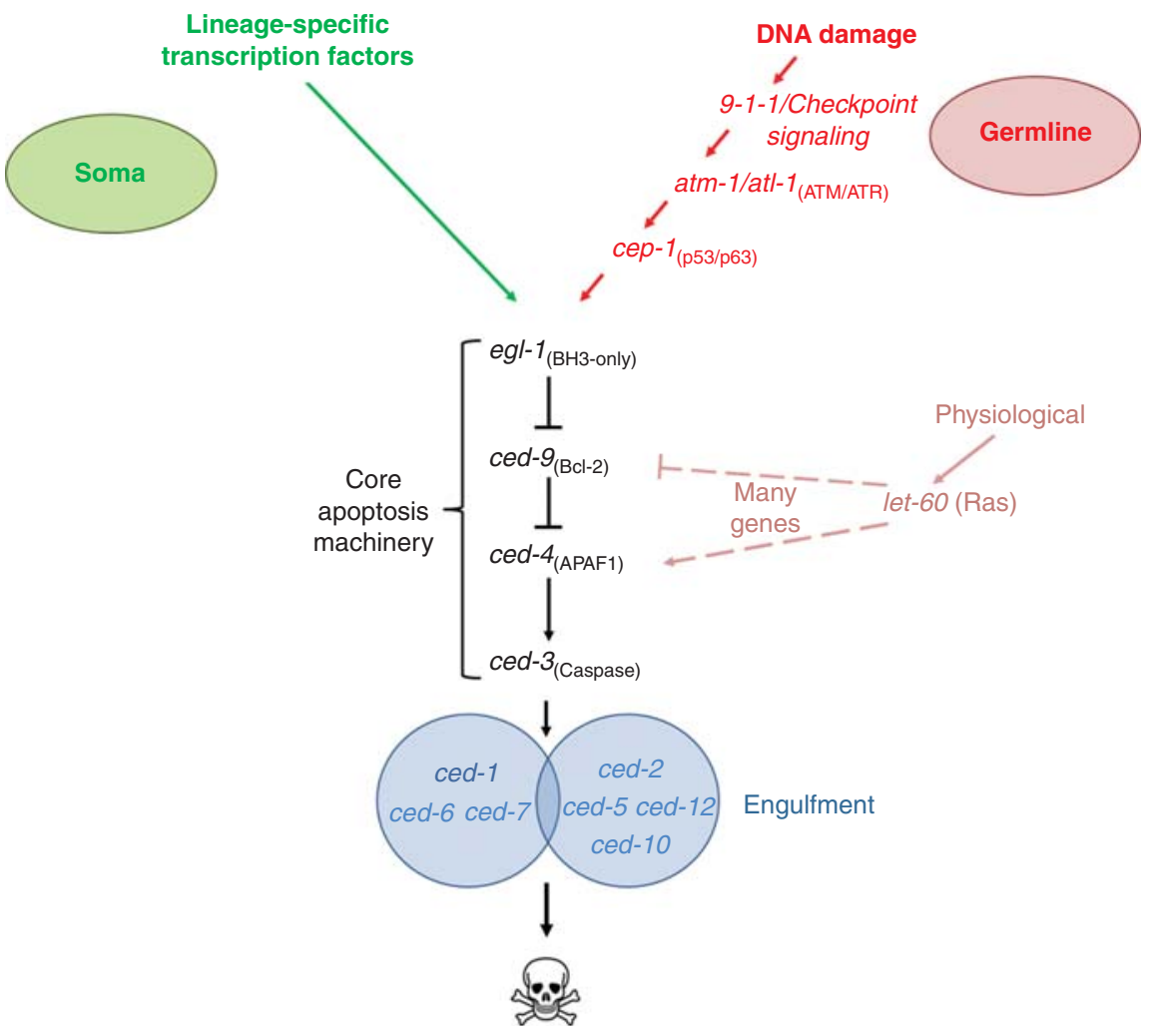

FIGURE 1. Apoptosis signaling in C. elegans. Somatic apoptosis uses the core machinery and is regulated by controlling the levels of egl-1 through lineage-specific transcription factors. Germline apoptosis can be broken into two categories: physiological and stress-induced. Stress-induced apoptosis (indicated as DNA damage) requires the activities of both cep-1 and egl-1, whereas physiological apoptosis is controlled by independent pathways that activate the core apoptotic proteins CED-4 and CED-3 (Gumienny et al. 1999). Following core apoptosis machinery activation and culminating in the activation of the CED-3 executioner caspase, DNA degradation and engulfment machinery is also activated (full components not shown), resulting in the complete death and removal of the cell.

and reagents are working properly. In addition, targeting known apoptosis genes that stimulate or repress apoptosis when knocked down is useful in establishing epistatic order for new apoptosis genes for which mutant strains are available. Whole-genome profiling studies are revealing previously undetected variations in the genomes of various $C$. elegans strains, many of which are predicted to disrupt gene function (Flibotte et al. 2010). Thus, it is also important to confirm that the apoptotic phenotype of a given mutant strain is actually caused by the suspected gene by either rescuing the phenotype with a transgene or validating with different mutant alleles. While rescue of a mutant phenotype by expression of a wild-type transgene is the desirable method to confirm that genotype corresponds to phenotype, it is technically challenging to express genes in the C. elegans germline. As an alternative, the RNAi feeding method can be used to confirm that ablation of a suspect gene in wildtype animals can recapitulate the apoptosis phenotype. Whenever possible, apoptosis phenotypes detected using RNAi should be confirmed using strains that contain loss-of-function alleles to the corresponding gene.

Stimulation of apoptosis with genotoxic stress can be achieved through a number of strategies. The source of toxicity should be selected appropriately. We outlined IR treatment here, as it is a common activator of the DNA damage response in the C. elegans germline and requires much less optimization than a drug dissolved in buffer, such as ENU. However, RNAi to the rad-51 gene causes double-strand breaks in DNA that can be used as an alternative to irradiation to activate the cep-1-dependent germline apoptosis signaling pathway (Lettre et al. 2004). By stimulating germline apoptosis via irradiation, the effects of a mutation (or gene ablation by RNAi) are exaggerated in proportion with the radiation dose. Of course, using an appropriate control for comparison is imperative, and 
B. Lant and W.B. Derry

provides verifiable and consistent baselines for stress-induced apoptosis (for both qualitative and quantitative metrics).

\section{RECIPES}

\section{Luria Bertani (LB) + Amp and Tet}

1. To prepare solid medium, mix $10 \mathrm{~g}$ of tryptone, $5 \mathrm{~g}$ of yeast extract, $10 \mathrm{~g}$ of $\mathrm{NaCl}$, and $15 \mathrm{~g}$ of agar, and bring to $1 \mathrm{~L}$ with $\mathrm{H}_{2} \mathrm{O}$. (To prepare liquid medium, combine all ingredients except agar.)

2. Autoclave for $30 \mathrm{~min}$.

3. Let cool for $1 \mathrm{~h}$ in a $55^{\circ} \mathrm{C}$ water bath.

4. Add $2 \mathrm{~mL}$ of $50 \mathrm{mg} / \mathrm{mL}$ ampicillin and $2 \mathrm{~mL}$ of $5 \mathrm{mg} / \mathrm{mL}$ tetracycline.

5. While the agar-containing medium is still warm, pour a thin layer $(\sim 0.5 \mathrm{~cm})$ into each Petri dish and let cool to solidify.

6. Store dishes or liquid medium at $4^{\circ} \mathrm{C}$ for up to $1 \mathrm{mo}$.

\section{M9 Buffer for Worms}

1. Dissolve $3 \mathrm{~g}$ of $\mathrm{KH}_{2} \mathrm{PO}_{4}, 6 \mathrm{~g}$ of $\mathrm{Na}_{2} \mathrm{HPO}_{4}$, and $5 \mathrm{~g}$ of $\mathrm{NaCl}$ in $1 \mathrm{~L}$ of $\mathrm{H}_{2} \mathrm{O}$.

2. Autoclave for $20 \mathrm{~min}$.

3. Add $1 \mathrm{~mL}$ of $1 \mathrm{M} \mathrm{MgSO}_{4}$.

4. Store at room temperature. After $2 \mathrm{wk}$, check for visible contamination before use.

\section{Nematode Growth Medium (NGM)}

1. For solid NGM, mix $3 \mathrm{~g}$ of $\mathrm{NaCl}, 2.5 \mathrm{~g}$ of peptone, and $20 \mathrm{~g}$ of agar and bring to $1 \mathrm{~L}$ with $\mathrm{H}_{2} \mathrm{O}$. (For liquid NGM, prepare without agar.)

2. Autoclave for $1 \mathrm{~h}$.

3. Let cool for $1 \mathrm{~h}$ in a $55^{\circ} \mathrm{C}$ water bath.

4. Add $1 \mathrm{~mL}$ of cholesterol ( $5 \mathrm{mg} / \mathrm{mL}$ in ethanol), $1 \mathrm{~mL}$ of $1 \mathrm{M} \mathrm{CaCl}, 1 \mathrm{~mL}$ of $1 \mathrm{M}$ $\mathrm{MgSO}_{4}$, and $25 \mathrm{~mL}$ of $1 \mathrm{M}\left(\mathrm{pH}\right.$ 6.0) $\mathrm{KPO}_{4}$, mixing after each addition.

5. Using an automated plate pourer (peristaltic pump), pour the medium into sterile plastic plates to set. During pouring, keep the NGM on a hot plate with stirrer to prevent the medium from solidifying.

6. Store NGM plates at $4^{\circ} \mathrm{C}$ until use. Seed NGM plates with bacteria the day after pouring. Warm the plates to room temperature before adding the worms. (For liquid NGM, store at room temperature for up to 1 mo. Regularly check for excess cloudiness to ensure bacterial contamination is absent; this is particularly important for liquid RNAi cultures.)

\section{RNAi Medium}

1. Prepare $1 \mathrm{~L}$ of nematode growth medium (NGM) by following Steps $1-4$ of the NGM recipe. $<\mathrm{R}>$

2. Add $2.5 \mathrm{~mL}$ of $0.1 \mathrm{M}$ isopropylthio- $\beta$-galactoside (IPTG) and $500 \mu \mathrm{L}$ of $50 \mathrm{mg} / \mathrm{mL}$ carbenicillin.

3. Using an automated plate pourer (peristaltic pump), pour the medium into sterile plastic plates to set. During pouring, keep the medium on a hot plate with stirrer to prevent the medium from solidifying.

4. Store RNAi plates for up to $1 \mathrm{mo}$ at $4^{\circ} \mathrm{C}$. 


\section{REFERENCES}

Flibotte S, Edgley ML, Chaudhry I, Taylor J, Neil SE, Rogula A, Zapf R, Hirst M, Butterfield Y, Jones SJ, et al. 2010. Whole-genome profiling of mutagenesis in Caenorhabditis elegans. Genetics 185: 431-441.

Gumienny TL, Lambie E, Hartwieg E, Horvitz HR, Hengartner MO. 1999. Genetic control of programmed cell death in the Caenorhabditis elegans hermaphrodite germline. Development 126: 1011-1022.

Kumsta C, Hansen M. 2012. C elegans rrf-1 mutations maintain RNAi effciency in the soma in addition to the germline. PloS ONE 7: e35428.

Lant B, Derry WB. 2014. Visualizing apoptosis in embryos and the germline of Caenorhabditis elegans. Cold Spring Harb Protoc doi: 10.1101/pdb. prot080218.

Lehner B, Calixto A, Crombie C, Tischler J, Fortunato A, Chalfie M, Fraser AG. 2006. Loss of LIN-35, the Caenorhabditis elegans ortholog of the tumor suppressor p105Rb, results in enhanced RNA interference. Genome Biol 7: R4.
Lettre G, Kritikou EA, Jaeggi M, Calixto A, Fraser AG, Kamath RS, Ahringer J, Hengartner MO. 2004. Genome-wide RNAi identifies p53-dependent and -independent regulators of germ cell apoptosis in C. elegans. Cell Death Differ 11: 1198-1203.

Sijen T, Fleenor J, Simmer F, Thijssen KL, Parrish S, Timmons L, Plasterk RH, Fire A. 2001. On the role of RNA amplification in dsRNA-triggered gene silencing. Cell 107: 465-476.

Simmer F, Tijsterman M, Parrish S, Koushika SP, Nonet ML, Fire A, Ahringer J, Plasterk RH. 2002. Loss of the putative RNA-directed RNA polymerase RRF-3 makes C. elegans hypersensitive to RNAi. Curr Biol 12: 1317-1319.

Stiernagle T. Maintenance of C. elegans. in WormBook: The online review of C. elegans biology (ed. The C. elegans Research Community). WormBook. 


\section{Induction of Germline Apoptosis in Caenorhabditis elegans}

Benjamin Lant and W. Brent Derry

Cold Spring Harb Protoc; doi: 10.1101/pdb.prot080192

\begin{tabular}{cc}
$\begin{array}{r}\text { Email Alerting } \\
\text { Service }\end{array}$ & Receive free email alerts when new articles cite this article - click here. \\
\hline $\begin{array}{c}\text { Subject } \\
\text { Categories }\end{array}$ & Browse articles on similar topics from Cold Spring Harbor Protocols. \\
& Apoptosis Assays (73 articles) \\
& C. elegans (45 articles) \\
& Cell Biology, general (1382 articles) \\
& Developmental Biology (728 articles) \\
& RNA (317 articles) \\
& RNA Interference (RNAi)/siRNA (123 articles) \\
\hline
\end{tabular}

